NASA Technical Memorandum 106479

AIAA-94-0280

\title{
Focused Schlieren Flow Visualization Studies of Multiple Venturi Fuel Injectors in a High Pressure Combustor
}

K.S. Chun

National Aeronautics and Astronautics

Lewis Research Center

Cleveland, Ohio

R.J. Locke

Sverdrup Technology, Inc.

Lewis Research Center Group

Brook Park, Ohio

and

C.M. Lee and W.J. Ratvasky

National Aeronautics and Astronautics

Lewis Research Center

Cleveland, Ohio

Prepared for the

32nd Aerospace Sciences Meeting and Exhibit

sponsored by the American Institute of Aeronautics and Astronautics

Reno, Nevada, January 10-13, 1994 


\title{
Focused Schlieren Flow Visualization Studies of a Multiple Venturi Fuel Injectors in a High Pressure Combustor
}

\author{
K.S. Chun \\ National Aeronautics and Space Administration \\ Lewis Research Center \\ Cleveland, Ohio 44135 \\ R.J. Locke \\ Sverdrup Technology, Inc. \\ Lewis Research Center Group \\ Brook Park, Ohio 44142 \\ C.M. Lee and W.J. Ratvasky \\ National Aeronautics and Space Administration \\ Lewis Research Center \\ Cleveland, Ohio 44135
}

\begin{abstract}
$\underline{\text { Abstract }}$
Multiple venturi fuel injectors have been used to obtain uniform fuel distributions, better atomization and vaporization in the premixing/prevaporizing section of a lean premixed/prevaporized flame tube combustor. A focused Schlieren system, was used to investigate the fuel/air mixing effectiveness of various fuel injection configurations. The Schlieren system was focused to a plane within the flow field of a test section equipped with optical windows. The focused image plane was parallel to the axial direction of the flow and normal to the optical axis. Images from that focused plane, formed by refracted light due to density gradients within the flow field, were filmed with a high-speed movie camera at framing rates of 8,000 frames per second (fps). Three fuel injection concepts were investigated by taking high-speed movies of
\end{abstract}

the mixture flows at various operating conditions. The inlet air temperature was varied from $600{ }^{\circ} \mathrm{F}$ to $1000{ }^{\circ} \mathrm{F}$, and inlet pressures from 80 psia to 150 psia. Jet-A fuel was used typically at an equivalence ratio of 0.5 . The intensity variations of the digitized Schlieren images were analytically correlated to spatial density gradients of the mixture flows. Qualitative measurements for degree of mixedness, intensity of mixing, and mixing completion time are shown. Various mixing performance patterns are presented with different configurations of fuel injection points and operating conditions.

\section{$\underline{\text { Introduction }}$}

The adverse impact on the Earth's atmosphere of various man-made chemicals has been a great concern to the world today. 
Research currently in progress at the NASA Lewis Research Center is concerned with reducing emissions, especially oxides of nitrogen $\left(\mathrm{NO}_{\mathrm{x}}\right)$ from future aircraft engines. Two low $\mathrm{NO}_{x}$ combustor concepts appear to hold promise for meeting emission goals. ${ }^{1,2}$ One is a Lean Premixed Prevaporized (LPP) combustor. Successful application of LPP combustion requires a high degree of mixing and vaporization of the fuel before combustion occurs. Numerous flame tube experiments have demonstrated the advantages of multiple venturi fuel injectors in preparing uniform fuel/air mixtures. It is desirable to have as many fuel injection points as possible in order to produce uniform fuel/air mixtures for reducing $\mathrm{NO}_{\mathrm{x}}$ emissions. However, a large number of injectors is not cost effective. Optimizing the number of injection points requires a non-intrusive investigation of the fuel/air distribution, particularly in high pressure and temperature flow fields. ${ }^{3-7}$ This report presents a non-intrusive method of investigating nonuniformity of fuel/air mixtures in an LPP flame tube using a focused Schlieren system and digital image analysis.

\section{Focused Schlieren System}

An important feature of the Schlieren technique which allowed its implementation into the study described herein is its application to line-of-sight experimental configurations. Another desired attribute is that the technique senses density gradients inherent in the flow field and therefore does not require seeding. When liquid fuel (JetA) is injected into the preheated inlet air stream, the fuel mixes with the air and undergoes atomization and vaporization due to aerodynamic breakup and heat transfer processes, resulting in density gradients in the flow field. Initial attempts to obtain flow field images with a conventional Schlieren system failed since the images obtained with this system represented the integrated effects of all density gradient across the test section, as well as all gradients, external to the test section (e.g. free convective flow off the hot pipe). Subsequent use of a focused Schlieren system proved successful, both at eliminating unwanted external density gradients and at visualizing the density gradient present within the test section. The actual optical configuration used in the present study, is an adaptation of the improved large field focusing Schlieren system developed by Weinstein. $^{8}$

Figure 1 shows a schematic of the focused Schlieren system setup used in this study. White light from a 150 watt tungsten halogen lamp diffuses through a $1.5 \mathrm{~cm}$ iris and illuminates the Fresnel lens which creates a planar distribution of point sources. A source grid, composed of vertical slits, masks the planar light distribution, thus forming a series of parallel-line light sources. The light then passes into the premixing/prevaporizing section through $2.5^{\prime \prime}$ diameter, 1.25" thick optical windows and irradiates the flow field defined by the front focal plane of a camera lens. The lens forms the flow field's image on a frosted glass plate located at the conjugate focal plane of the lens via the cutoff grid. The focal planes are parallel to the axial flow direction and normal to the optical axis.

Figure 2 exhibits the cutoff grid, which is the photographic negative of the source grid. The cutoff grid can mask all light rays passing through the flow field, resulting in no image; it can transmit a majority of all 
rays passing through the flow field, resulting in an overly bright or overexposed image; or, it can pass some unrefracted rays and those rays which experience refraction due to changes in the density, thereby producing the Schlieren effect. The fine adjustment of this cutoff grid controls the amount of light rays striking the imaging plate and hence, the sensitivity of the Schlieren effect. A $16 \mathrm{~mm}$ high speed movie camera photographs the Schlieren images from the frosted glass plate at a frame speed of $8000 \mathrm{fps}$. Simultaneously, a gated CCD video camera provides a real-time display of the Schlieren images on a video monitor at a shutter speed of $0.1 \mathrm{~ms}$. A television camera not shown in figure 1 , displays real time video of the windows and premixing section interior.

\section{Test Rig and Experiments}

The test rig used for this investigation, and described in detail elsewhere, ${ }^{9,10}$ is shown schematically in Figure 3. The rig was designed for fuel-lean combustion experiments with inlet air pressurized up to 17 atm and preheated up to $1100^{\circ} \mathrm{F}$. This high pressure/temperature rig consists of a fuel injection module, premixing and prevaporizing section, flame holder, and combustion section. The combustion section is square with a flow cross sectional area of $58 \mathrm{~cm}^{2}$ ( $9 \mathrm{in}^{2}$ ). The length of the premixing and combustion sections are 27 $\mathrm{cm}$ ( 10.5 in.) and $74 \mathrm{~cm}$ ( 29 in.), respectively. Line-of-sight optical windows were installed in the premixing/prevaporizing section, $3.8 \mathrm{~cm}$ ( 1.5 in ) downstream from the tip of the multiple venturi injector module, as measured from the center of the windows. Silica windows $6.35 \mathrm{~cm}$ ( 2.5 in ) in diameter, and $3.18 \mathrm{~cm}$ ( 1.25 in ) thick were used.
The perforated-plate flame holder, located $10.2 \mathrm{~cm}$ (4 in) downstream from the center of the windows, contained 36 holes producing an open flow area equivalent to $20 \%$ of the total inlet duct cross sectional area. The multiple venturi fuel injector module is shown in Figure 4. The injector module embodies 16 square venturi air passages each of which incorporates a 0.7 $\mathrm{mm}(0.027 \mathrm{in})$ ID fuel tube through which Jet-A fuel was injected. Fuel injection at the throat of the module was accomplished in order to obtain better fuel atomization with the highest possible inlet air velocity. The fuel/air flow visualization experiments were conducted utilizing the fuel injector configurations illustrated in figure 4: a $4 \mathrm{x}$ 4 matrix of all sixteen injectors; a staggered arrangement of 8 injectors; and, 8 injectors located in the top two rows of the module.

Operating conditions for the test runs are recorded in Table 1 . In the table $T_{3}$ is the combustor inlet temperature, $\mathrm{P}_{3}$ is the combustor inlet pressure, $m_{\text {air }}$ is the mass flow rate, F/A is the fuel air ratio, and $\mathrm{V}_{\text {ref }}$ is the reference velocity.

\section{$\underline{\text { Results }}$}

A contiguous order of 10 frames was selected from each roll of $16 \mathrm{~mm}$ high speed movie film for each respective configuration and condition. Each frame was digitized into 8 bits per pixel gray intensity with a high resolution CCD video camera and a PC frame grabber. Digital image processing, such as background subtraction, pseudo coloring and computation of mean and standard deviation of intensity variations, were accomplished on a SPARC workstation utilizing PV-WAVE, from Precision Visuals Inc.. ${ }^{11}$ With the use of the Lorenz-Lorenz 
relation and Gladstone-Dale equation, the intensity variations can be directly correlated to the density gradients of the mixture flow. ${ }^{12}$

Typical image processing such as background subtraction, boxcar average filtering and pseudo coloring enhancements are shown in Figure 5. A background image of only the preheated inlet air flow (flow direction is from left to right) is shown in 5(a). A "raw" image, acquired when using the sixteen fuel injector configuration and $400^{\circ} \mathrm{F}$ inlet air, is shown in $5(\mathrm{~b})$. For the purposes of the present study, a "raw" image is defined as an image upon which no background subtraction or normalization routine has been performed. When the pseudo-color enhanced image in 5(b) undergoes background subtraction, the image in 5(c) is obtained. When 5(c) is filtered according to the average intensity magnitude of each pixel within the frame, the image presented in $5(\mathrm{~d})$ is produced. This image shows the density gradients generated as the air and fuel mix. Low intensity values are equated with low density gradients which represent slightly mixed or unmixed regions shown as shades of blue. High intensity values, colored in yellows and reds, indicate regions of high density gradients where intense mixing is occurring. Computation of mean and standard deviation of the image pixel intensities leads to a qualitative comparison of degrees of mixedness.

A qualitative derivation of degrees of mixedness is illustrated in Figure 6. Vertical lines are drawn at various locations along the imaged test section. The mean and standard deviation for each line are given to the left of the raw and filtered images. The standard deviation in the mid image positions are higher than those at either the upstream or downstream positions. This infers that density gradients are changing on a large scale, and that the mixing activity increases from the left to some maximum value, followed by a decrease as the fuel and air become well mixed and flow downstream. The mixing tends toward completion as the standard deviation decreases.

Figure 7 presents a comparison of 3 sequential images of the 3 different fuel injector configurations, with each image sequence collected under comparable experimental conditions. The time interval between each succeeding image is $0.125 \mathrm{~ms}$. The top image sequence is the fuel/air mixture flow field resulting from 16-point fuel injection. The middle sequence is the flow field resulting from the staggered 8point injection configuration. The lower sequence is produced by the top-two-rowfueled 8-point injector arrangement. It is evident from Figure 7 that the 16-point fuel injection scheme produces strong mixing and uniform density gradient distribution. The staggered, 8-point fuel injection scheme also suggests strong mixing but does not exhibit uniform density gradient distribution. The top two row, 8-point injection configuration shows strong mixing towards the lower third of the image sequence and a non-uniform distribution of density gradients.

This trend is given further support by the gradient intensity values along the flow direction of each configuration shown in figure 8. If a horizontal line is drawn over the Schlieren image parallel to the flow direction and the density gradient values are plotted versus the location of each pixel on the horizontal line, the graph shown on the right of each image can be obtained. The pixel intensity variation is proportional to the density gradient fluctuation. Therefore, each 
graph plots density gradient fluctuation versus axial location. The amplitude of the density gradient fluctuations is related to the fuel density. Higher fuel density equates to higher gradient fluctuation amplitudes. In the top image (16-point injection) the amplitude of the density gradient fluctuation, as defined by the pixel intensity, is observed to be damping away toward the right (downstream).

The case is similar for the middle image (staggered 8-point injection), with the caveat that the amplitudes of the density gradient fluctuations are larger and take longer to damp out. However, the density gradient fluctuations along line $\mathrm{A}$ in the lower figure (top two row 8-point injection), appears to not dampen significantly over the width of the imaged flow field. These observations support the statement that mixing for the 16point and staggered 8-point injector configuration appears to be complete or nearing completion over the width of the imaged flow field, but mixing for the lower configuration (top two row 8-point injection) shows no evidence of nearing completion. The apparent damping of plot $\mathrm{A}$ in the lower figure, and the initial flatness for all plots is attributed to the extension of the lines beyond the limits of the actual image. Plot $\mathrm{B}$ in the lower figure is drawn through a region which is mostly $1000^{\circ} \mathrm{F}$ inlet air, and as expected demonstrates little density gradient variation.

An additional method to discern the mixing progress of each injector configuration is one in which the variation in density gradient intensity is observed over the frame-to-frame time interval of $0.125 \mathrm{~ms}$. This method, presented in Figure 9, uses a vertical line drawn normal to the flow direction in each of two sequential images for each injector configuration. The density gradient intensity at each individual pixel location in the first frame is subtracted from that of the succeeding frame. The variations in intensity at each pixel position is shown graphically next to each sequence. As in the examples shown here, all like configurations showed analogous trends. The 16-point injection displays a relatively unchanged pixel intensity across the flow field showing a rather homogenous mixture at this location in the premixing section. However, a similar plot for the staggered 8-point injection shows a large disparity between succeeding images, on the order of $70 \%$ greater than that exhibited by the 16-point injection. This result indicates a more heterogenous fuel/air mixture in this location. The top two row 8point injection scheme shows little variation in pixel intensity in the lower third of the image, which is consummate with the fact that there is only preheated air in this region, but large variations appear in the upper portion, again indicative of a heterogenous fuel/air mixture.

\section{$\underline{\text { Conclusion }}$}

This flow visualization study has demonstrated the efficacy of the focused Schlieren technique for obtaining useful information concerning the flow field of the fuel injection region of a lean premixed/prevaporized (LPP) flame tube combustor. Two-dimensional slices of the flow field were imaged to show the performance and effects of various fuel injector configurations. The results obtained in the present study indicate that the focused Schlieren system can be a useful tool to combustor designers for evaluating the uniformity of the flow fields produced by various fuel injectors. 
Future work will involve the application of the focused Schlieren technique to the combustor flow field in the LPP flametube, through thin film-cooled windows, recently added to the combustion section.

\section{$\underline{\text { Acknowledgements }}$}

The authors wish to thank Jean Bianco, Dean Kocan, Wade Arida, and Dennis Kinzelman for their contributions in conducting the experimental portions of this investigation.

\section{$\underline{\text { References }}$}

1. Shaw, R.J., "Engine Technology Challenges for a $21^{\text {st }}$ Century High Speed Civil Transport", NASA TM104363, 1991.

2. Tacina, R.R., "Low $\mathrm{No}_{x}$ Potential of Gas Turbine Engines", AIAA-90-0550, 1990.

3. Tacina, R.R., "Performance of a Multiple Venturi Fuel-Air Preparation System" in Premixed Prevaporized Combustor Technology Forum, ed. Mularz, E.J., NASA CP-2078, 1979.

4. Ercegovic, D.B., "Effect of SwirlerMounted Mixing Venturi on Emissions of Flame-Tube Combustor Using Jet-A Fuel", NASA TP-1582, 1980.

5. Cooper, L.P., "Effect of Degree of Fuel Vaporization Upon a Premixed Partially Vaporized Combustion System", NASA TP-1582, 1980.

6. Lyons, V.J., "Fuel/Air Nonuniformity Effect on Nitric Oxide Emissions",
AIAA-81-0327, 1981.

7. Johnson, S.M., "Venturi Nozzle Effects on Fuel Drop Size and Nitric Oxide Emissions", NASA TP-2028, 1982.

8. Weinstein, L.M., "An Improved Large Field Focusing Schlieren System", AIAA-91-0567, 1991.

9. Lee, C.M., Kundu, K., and Acosta, W., "Jet-A Reaction Mechanism Study for Combustion Application", AIAA-912355, 1991.

10. Lee, Chi M.,"Lean Premixed Prevaporized Jet-A/Air Flame Tube Study", Cleveland State University, Cleveland, Ohio, University Microfilms International, Ann Arbor, MI, 1993.

11. Precision Visuals, Inc., PV-WAVE Technical Reference Manual, Version 4.2, 1992.

12. Fluid Mechanics Measurements, ed. Goldstein, R., Hemisphere Publishing Corp., 1983. 
TABLE 1.

Operating Conditions for Focused Schlieren Flow Visualization

\begin{tabular}{|c|c|c|c|c|l||}
\hline $\begin{array}{c}\mathrm{T}_{3} \\
\left({ }^{\circ} \mathrm{F}\right)\end{array}$ & $\begin{array}{c}\mathrm{P}_{3} \\
(\mathrm{psia})\end{array}$ & $\begin{array}{c}\mathrm{m}_{\text {air }} \\
(\mathrm{lb} / \mathrm{s})\end{array}$ & F/A & $\mathrm{V}_{\text {ref }}$ & $\begin{array}{c}\text { Fuel Injection } \\
\text { Method }\end{array}$ \\
\hline ROOM & 55 & 1.48 & & 92.7 & $\begin{array}{l}\text { Background } \\
\text { 8-point staggered. }\end{array}$ \\
\hline 1002 & 139 & 2.0 & 0.02 & 127 & 8-point staggered. \\
\hline 1000 & 113 & 2.0 & 0.04 & 160 & 8-point staggered. \\
\hline ROOM & 55 & 1.48 & & 92.7 & $\begin{array}{l}\text { Background. Top two row } \\
\text { 8-point fuel injection }\end{array}$ \\
\hline 1002 & 125 & 2.0 & 0.028 & 140 & $\begin{array}{l}\text { Top two row 8-point fuel } \\
\text { injection }\end{array}$ \\
\hline 401 & 70 & 1.69 & 0.034 & 123 & 16 point fuel injection \\
\hline 1002 & 133 & 2.0 & 0.040 & 130 & 16 point fuel injection \\
\hline \hline
\end{tabular}




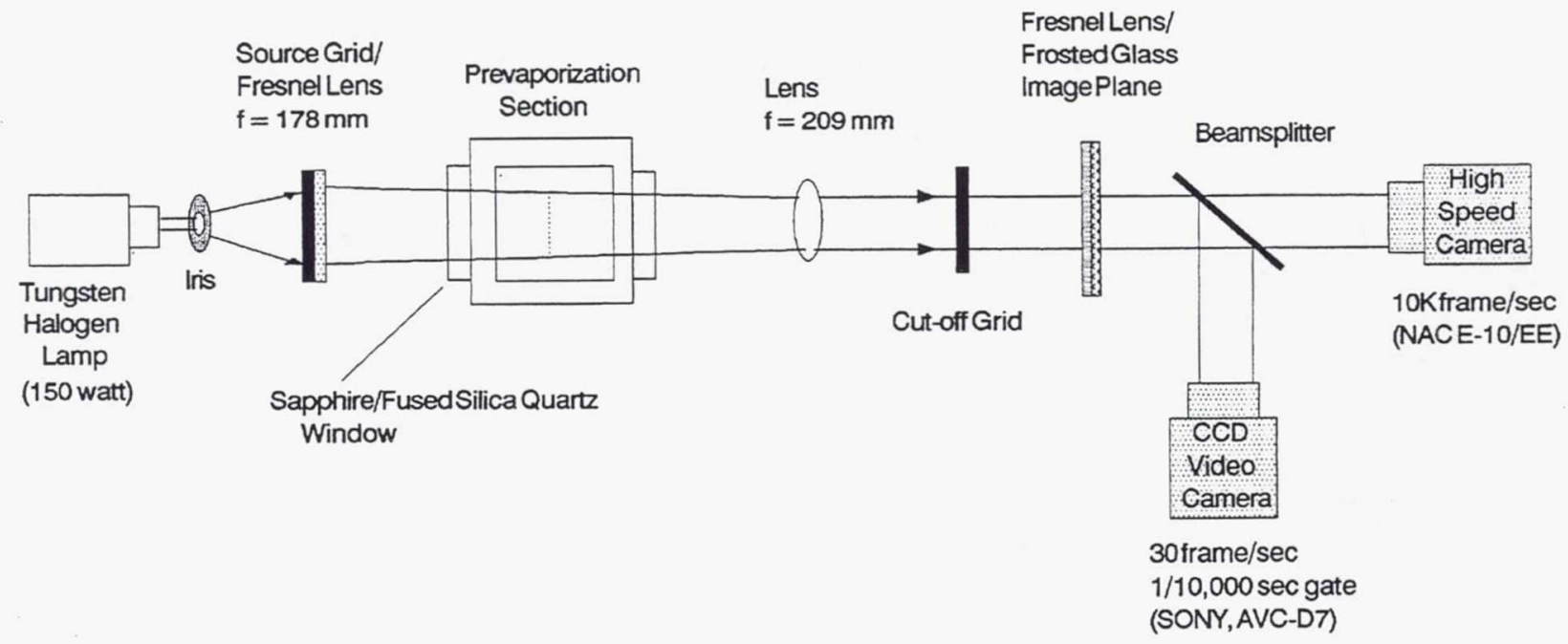

Fig. 1 Focused Schlieren Aparatus.

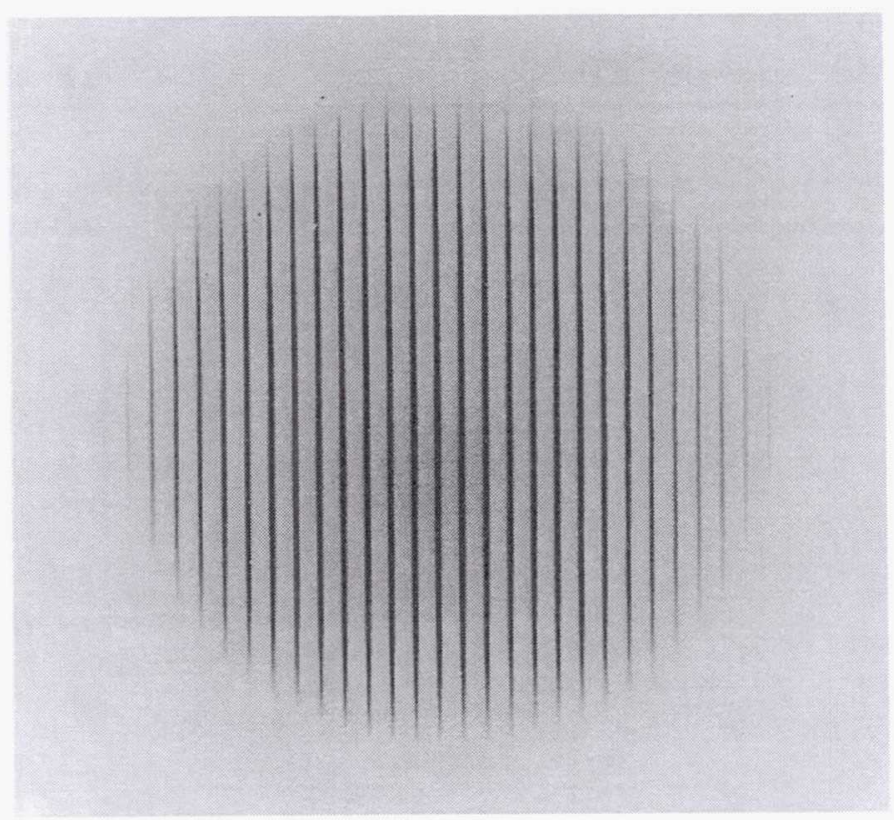

Fig. 2 Cutoff Grid. 


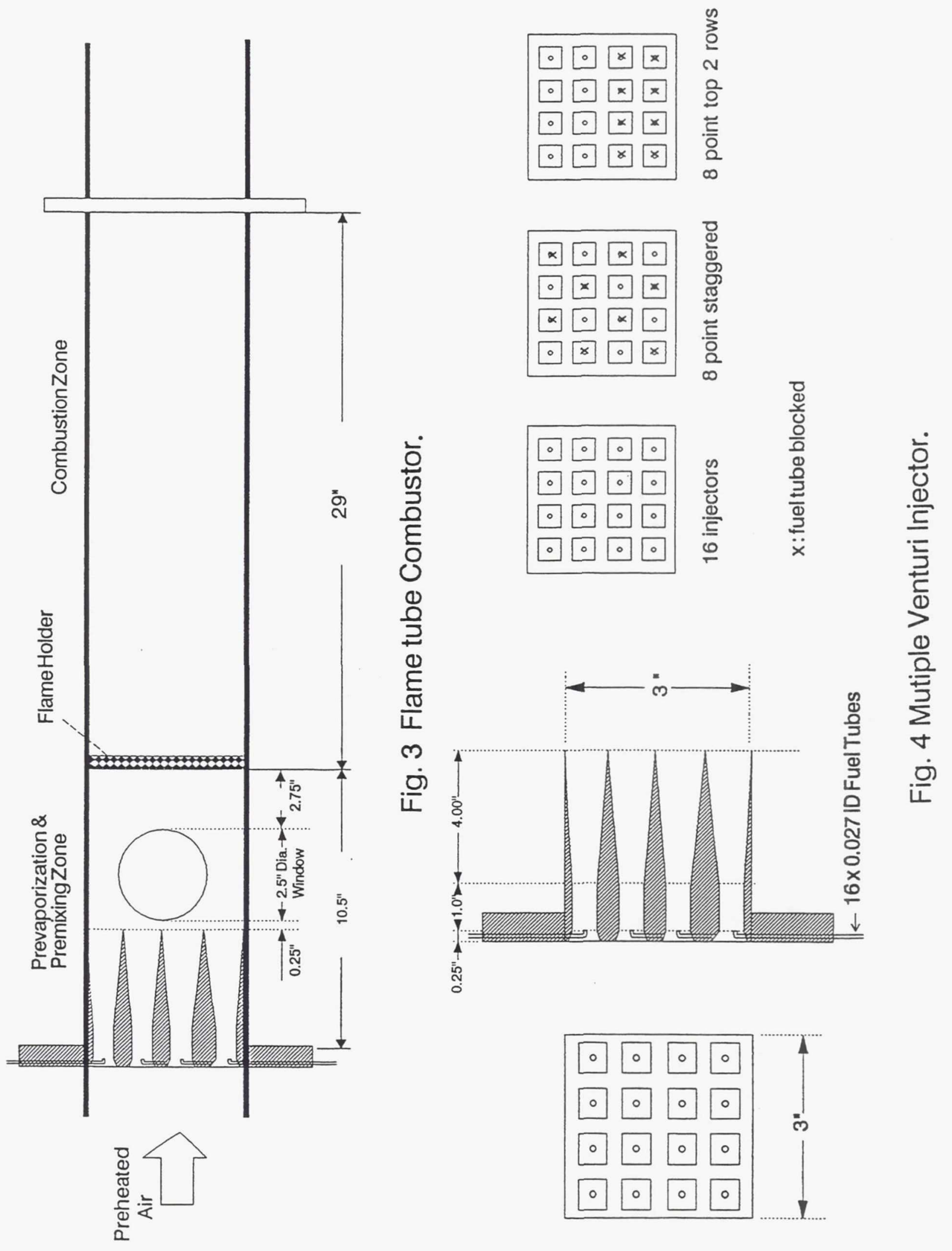


Page intentionally left blank 


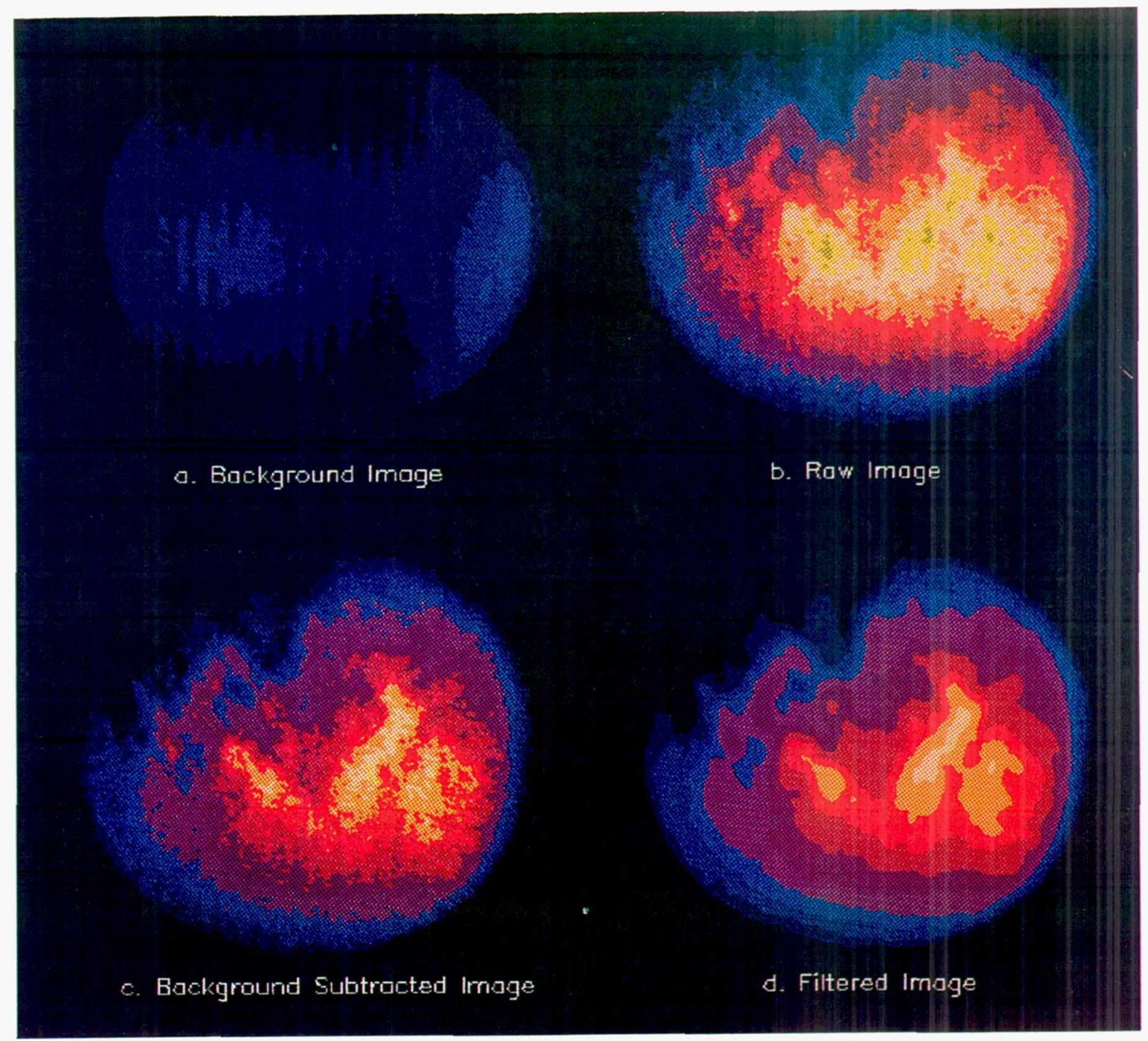

Fig. 5 Images are background substracted and filtered. 
Page intentionally left blank 
Line A

Mean : 79.8969

Standard Deviation : 34.3762

Line $\mathrm{B}$

Mean : 117.071

Standard Deviation : 64.3442

Line $\mathrm{C}$

Mean : 128.522

Standard Deviation : 60.2685

Line [0

Mean : 151.295

Standard Deviation : 57.7468

Line $E$

Mean : 109.714

Standard Deviation : 49.4204

\section{(Sixteen Point Fuel Injection)}

Line A

Mean : 0.730113

Standard Deviation : 0.316428

Line B

Mean : 1.06938

Standard Deviation : 0.584222

Line $\mathrm{C}$

Mean : 1.17255

Standard Deviation : 0.553764

Line [

Mean : 1.38462

Standard Deviation : 0.532021

Line $E$

Mean : 1.00669

Standard Deviation : 0.453712

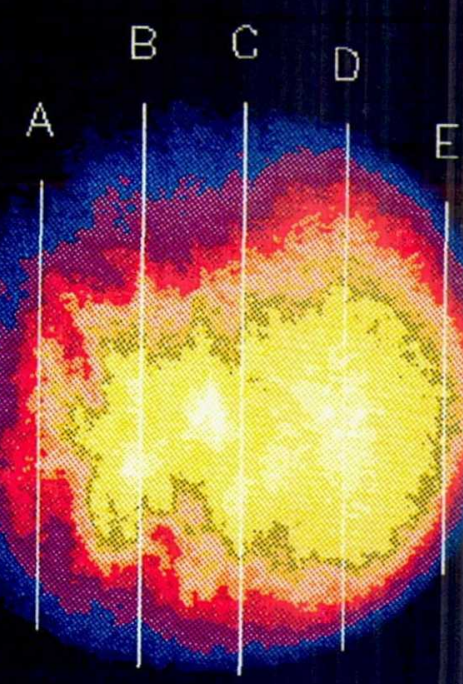

‥ Raw Image

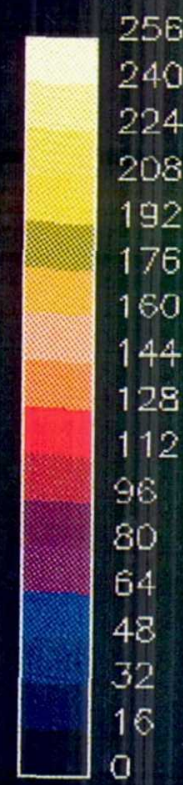

B C

256

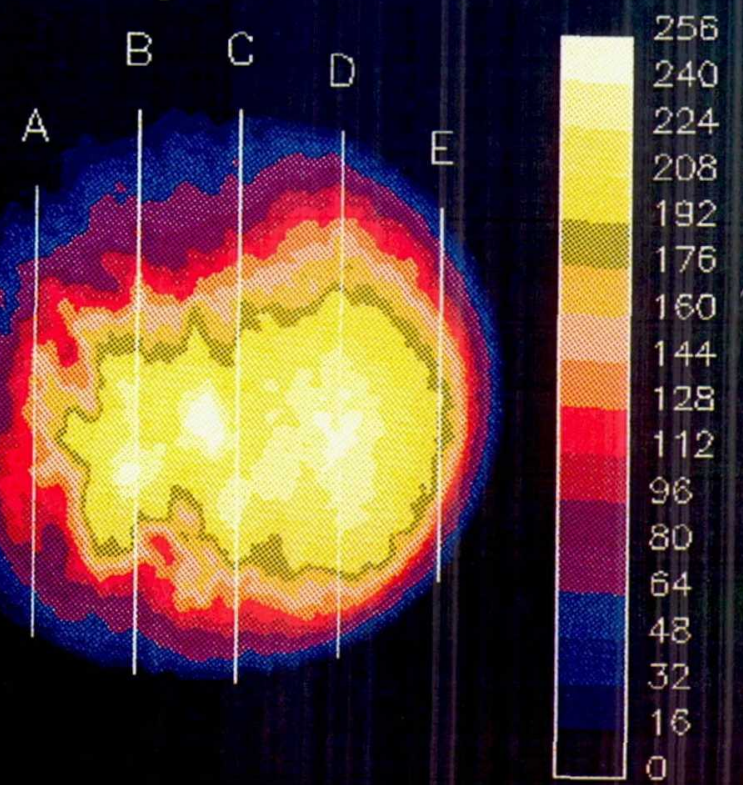

b. Filtered and Normalized Image sxtr_j19h1.img

Fig. 6 Standard Deviation Decreases as Mixing Completes. 
Page intentionally left blank 
Sixteen Point Fuel Injection

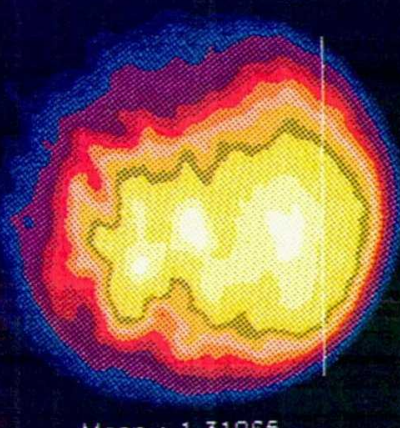

Mean : 1.31065

Standard Deviation : 0.526138

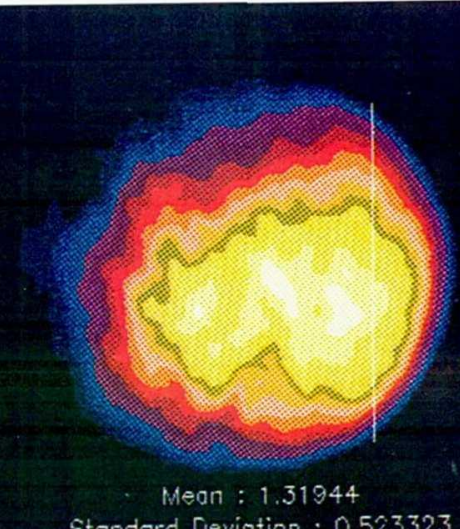

Standard [eviation : 0.523323

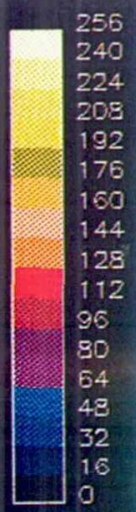

Stendard Deviation : 0.533218

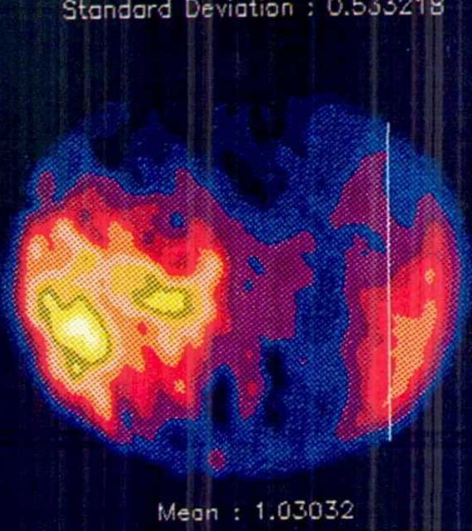

Standard Deviation : 0.368788

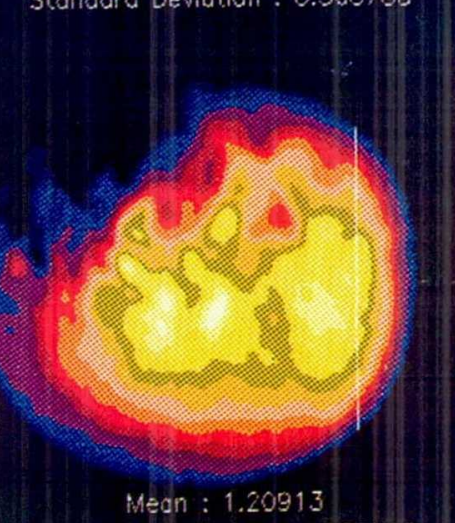

Standard Deviation : 0.389006

Fig. 7 Three Consecutive Frame Images for Three Different Injections. 
Page intentionally left blank 

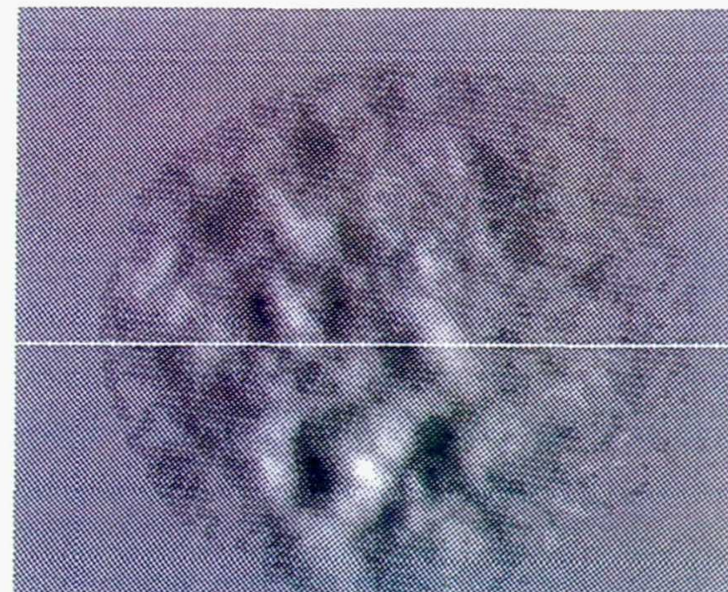

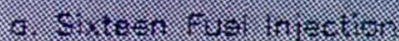

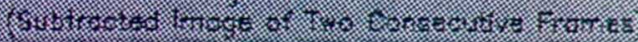
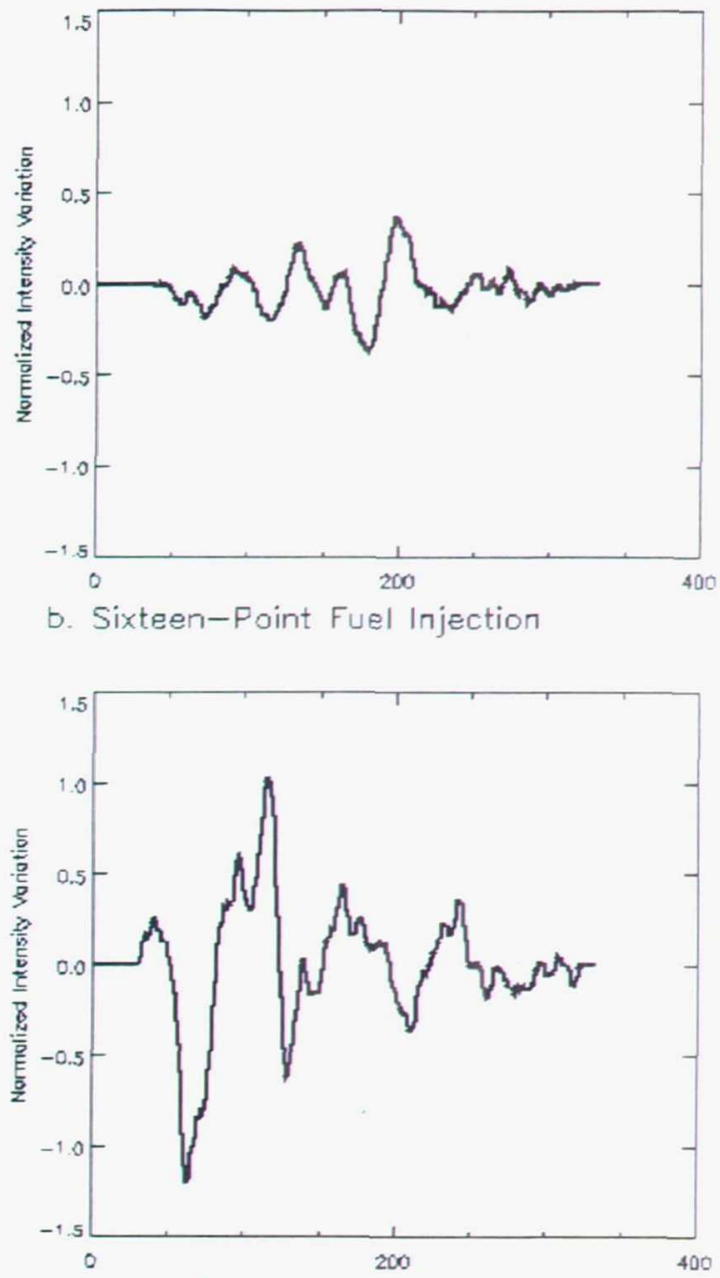

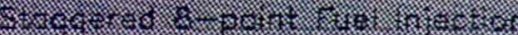

i.

d. Stoggered 8-point Fuel Injection

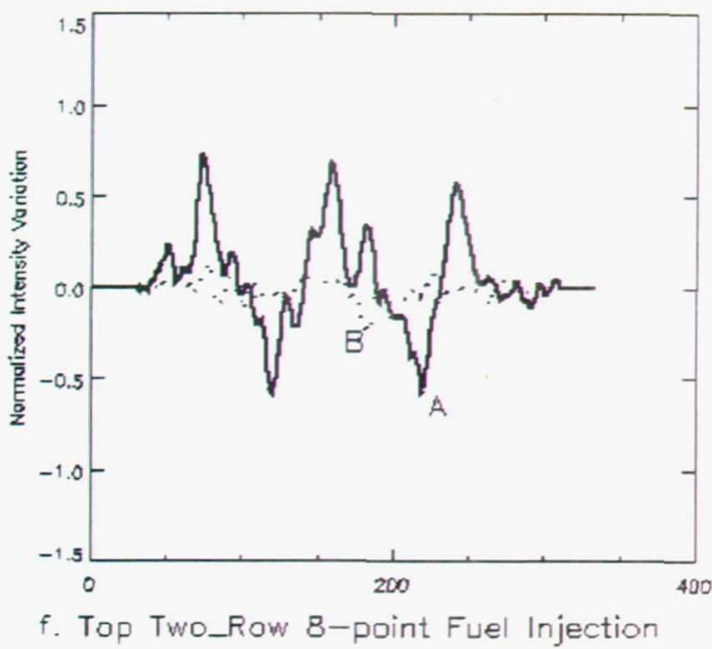

Fig. 8 Normalized Density Fluctuations in Axial Flow Direction. 
Page intentionally left blank 


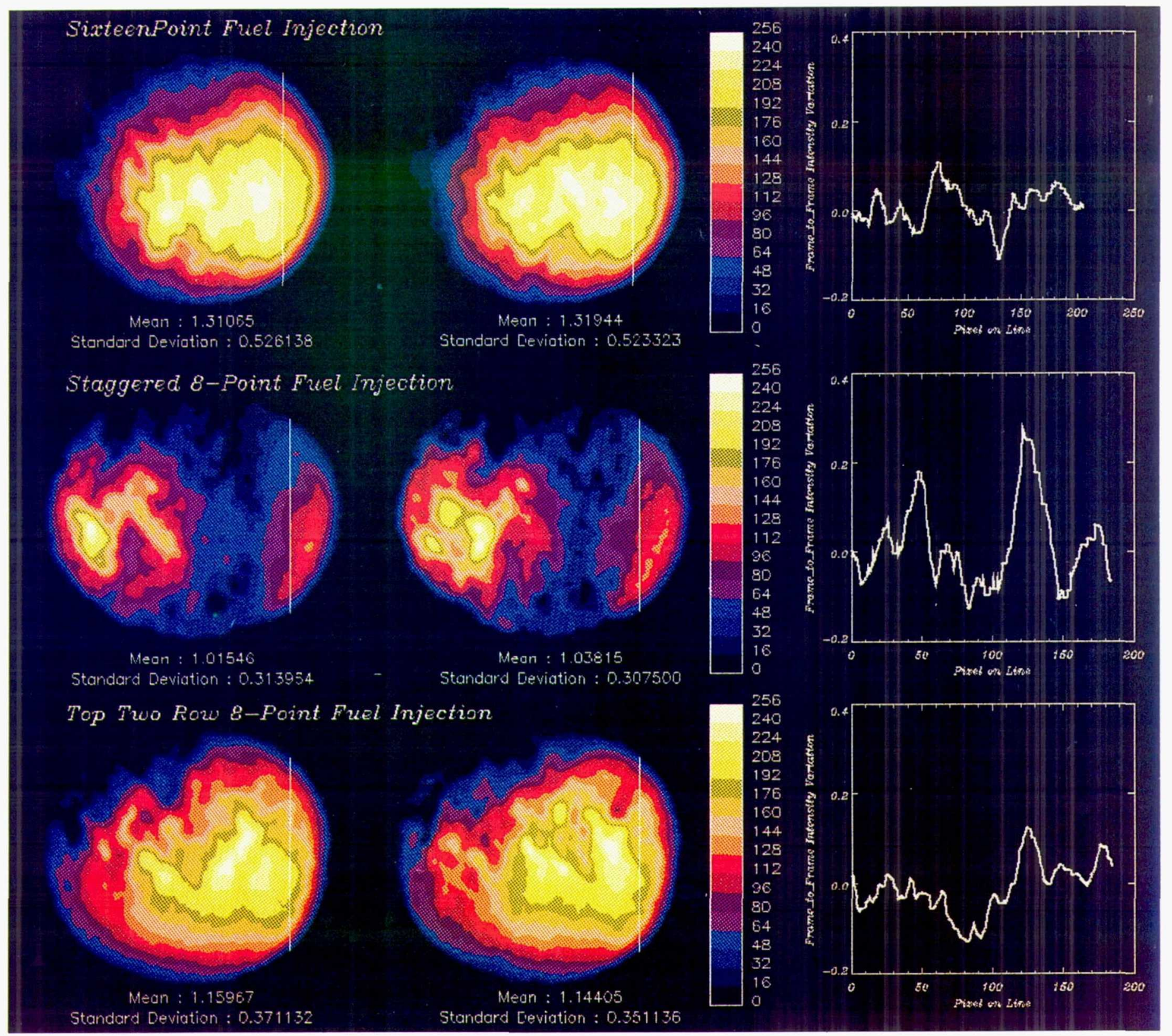

Fig. 9 Density Gradient Change at an Axial Location in a Frame Period. 
Page intentionally left blank 

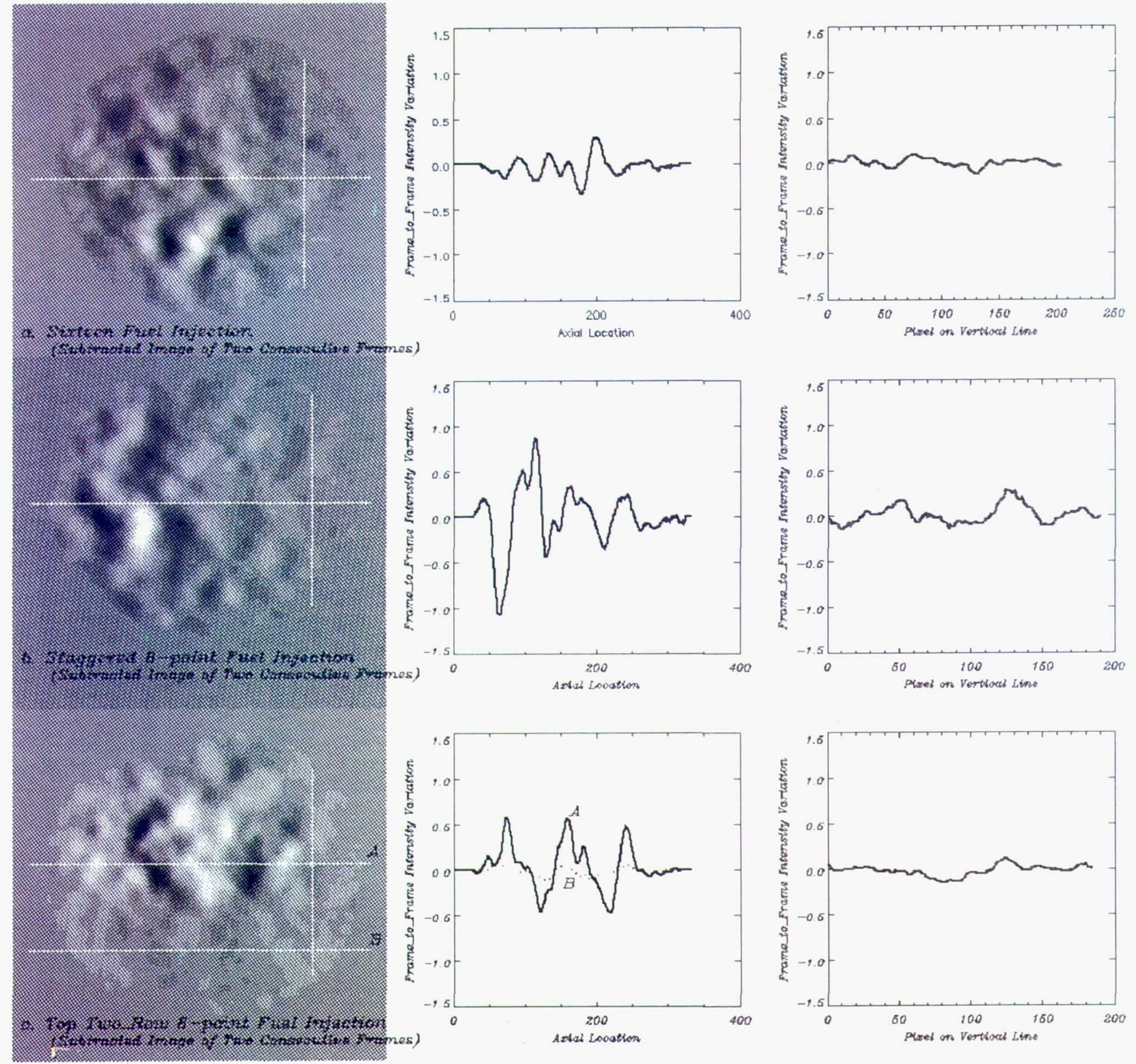

Fig. 10 Axial and Radial Density Gradient Fluctuations. 


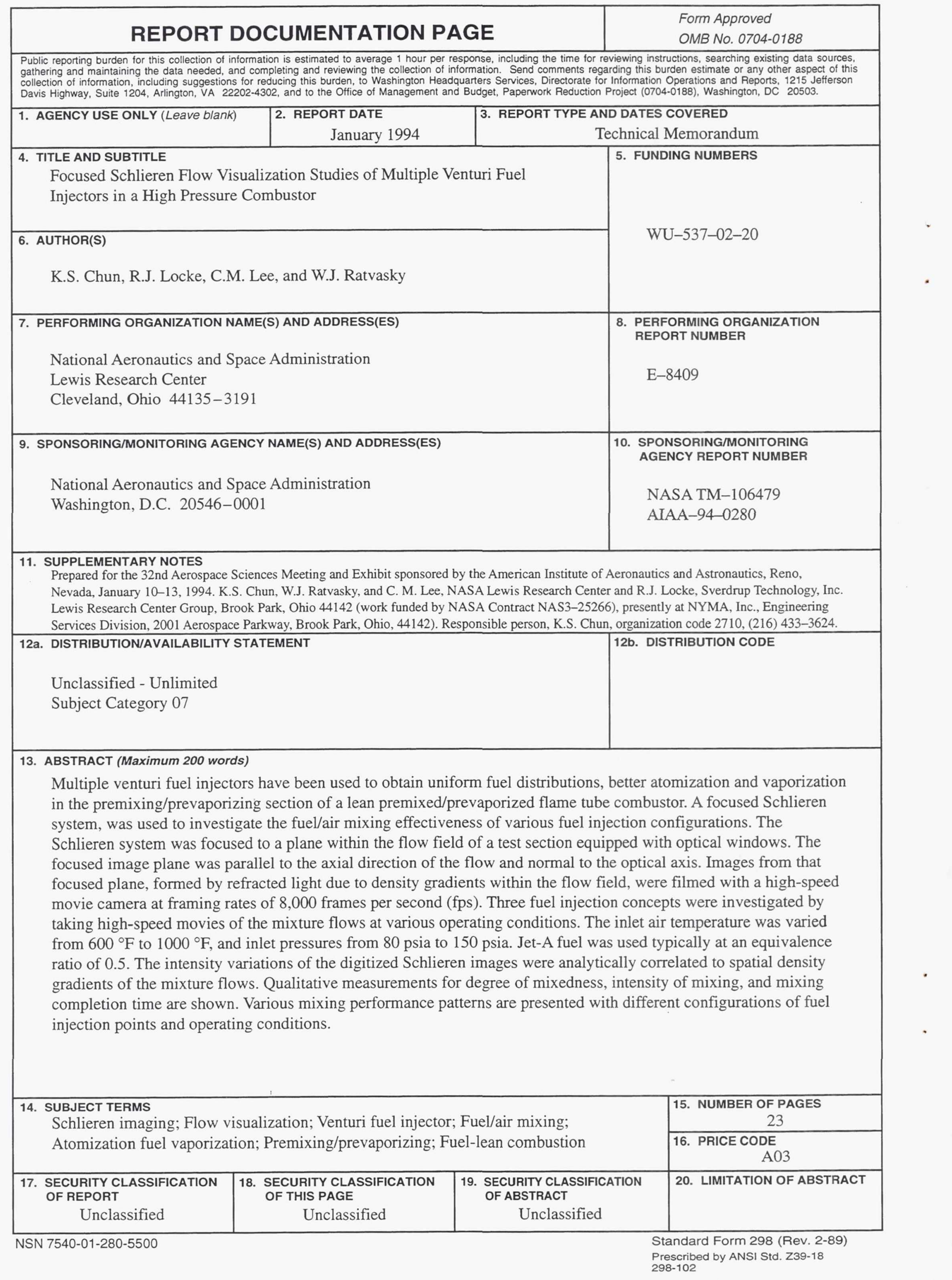

